\title{
Hydration Strategies for Elite Soccer Players
}

\author{
Haniel Soares Fernandes* \\ Estácio de Sá College, Nutrition department, São Gabriel da Palha College, Brazil
}

*Corresponding author: Haniel Soares Fernandes, Estácio de Sá College, Nutrition departament, Fortaleza, São Gabriel da Palha College, Nutrition, metabolism e physiology in sport, Espírito Santo, Brazil

\begin{abstract}
As soccer is sport with few opportunities to stop for rehydration during matches, strategies that help athletes and involved professionals with this athletes are highly necessary to guide with proposals how to help rehydrate the athlete before, during and after the matches, maintaining their performance and greating sport quality. However, the consumption of isotonic or hypotonic drinks in concentration 0.5 to $0.7 \mathrm{~g}$ sodium / $\mathrm{L}$ and with 4 to $6 \%$ carbohydrates (CHO) can be welcome before match, also isotonic drinks in concentration 0.5 to $0.7 \mathrm{~g}$ of sodium / L of water with 6 to $9 \%$ CHO offered every 15 or 20 minutes are important during match and hypertonic drinks in concentration 1 to $1.5 \mathrm{~g}$ of sodium / L with 9 to $10 \%$ should soon be ingested after the matches.
\end{abstract}

\section{Introduction}

Practiced by more than 240 million individuals, soccer is considered the most popular sport in the world [1]. On the 90 minutes match, there're sprints, changes in direction, jumps, accelerations and decelerations [2] characterizing this sport as prolonged duration intermittent exercise [3]. At the match end or on most demanding moments, when there're attacks and counterattacks, total distance and high intensity tends to decrease due tiredness or athletes performance loss [2] related to losses through sweating of fluids containing sodium, potassium, magnesium, calcium and chloride, causing liquid deficits [4] hat can be restored by intake sports drinks with $\mathrm{CHO}$ combination and electrolytes that optimize restoration body fluids after activities over 80 minutes, such as soccer [5]. A study monitored 17 male athletes between arrival in stadium and end of the match, and found an average loss of body mass of $2.5 \pm 1.08 \mathrm{~kg}$, an average dehydration of $3.38 \pm 1.11 \%$ of body mass and an average sweat loss of $4448 \pm 1216 \mathrm{ml}$ in parallel to the average fluid intake of $1948 \pm 954 \mathrm{ml}$ [6]. There was significant dehydration during the game, aggravated by hypohydration. These findings corroborate with fact athletes dehydration is more intense in games compared with trainings [7] and covers rehydration individualization opportunities to minimize reductions in match performance and improve their quality [4]. Therefore, in this review some new recommendations are suggested for elite soccer players training and competing to help them avoid dehydration.

\section{The hydration process during soccer practice}

During physical activity, body temperature increases and contributes to heat exchanges in attempt to adjust body temperature [8]. When temperature and air humidity reach levels that affect athletes performance, their bodies use more water and energy to stay cool during exercise [9]. When they use water to relieve temperature, the body lose important electrolytes causing athlete to lose fluids and, consequently, weight. Therefore, to assess the athlete's hydration status it's necessary to check changes body weight. Because dehydration causes dry mouth, drowsiness or tiredness, decreased diuresis, muscle weakness, headache, and dizziness, including thirst from increased osmolarity of extracellular plasma fluid [8]. The American College of Sports Medicine filed a special communication on athletes hydration announcing that thirst isn't a good indicator of the need for hydration, as it only occurs after a deficit of approximately $2 \%$ weight loss through fluid loss being characterized as mild dehydration, with losses between 1 and 3\% body weight through sweat during exercise [10]. As the opportunities for drinking fluids during soccer match are limited [4] any break event should be well used to rehydrate during games 
[11]. When the soccer player doesn't use opportunities to rehydrate there may be a loss of performance through dehydration. As shown by a study involving 11 soccer players separated in conditions with no fluid intake, fluid intake and only mouth rinse fluid using a 45 minute cycle ergometer test at $90 \%$ individual ventilatory threshold followed by 45 minutes soccer match, which resulted significant impairment sport, worse rating of effort perceived and greater thirst in the condition that did not use fluids [12]. The fluids and electrolytes loss can influence muscle cramps [13] and possible hyponatremia events among athletes. Exercise-associated muscle cramp (EAMC) is painful involuntary muscle contraction [14] and exercise-associated hyponatremia (EAH) is plasma sodium concentration of $<135 \mathrm{mmol} / \mathrm{L}$ during or after activity [15]. EAMC and EAH are conditions that can happen during resistance exercise that could be directly related to athlete's hydration status. However, one study reported that muscle cramps don't start from dehydration alone, between 3 and 5\% dehydration there may be an increase in serum sodium concentration (149.5 $\pm 1.8 \mathrm{mmol} / \mathrm{L})$ compared to the euhydrated condition (141.9 $\pm 3.1 \mathrm{mmol} / \mathrm{L})$ [16]. In addition, to assess athletes' hydration index, other markers are used such as urine osmolarity, specific urine severity or 24-hour urinary volume [17]. This reflects recent volume of liquid ingested, instead of athlete's total hydration status, as ingestion of a large volume of water quickly dilutes plasma and causes kidneys to excrete diluted urine even if there is dehydration [18]. Making process of assessing and maintaining an athlete's hydration very cautious.

\section{Hydration before match}

In soccer, the total distance covered as well as player's position on the field is important for measuring body water losses and draw hydration strategies to minimize fluid losses during match. A study evaluated 28 male players regarding their hydration status when they arrived at the stadium for game and when they left after match and concluded that most athletes remain hypohydrated approximately $80 \%$ of the time [19]. A randomized, double-blind, crossover study recruited 15 soccer players to perform 90 minutes of specific soccer exercises and consume an electrolyte drink with $12 \%$ CHO or placebo and as a result, who consumed this drink significantly increased the acceleration average, average dribbling speed and average sprint speed [20]. Therefore, hydration program before departure will guarantee hydration by correcting fluids deficit before start activities. The recommendation for this includes ingesting 5 to $7 \mathrm{~mL} / \mathrm{kg}$ of body weight fluids 4 hours before departure, but if individual doesn't produce urine, or the urine is dark or concentrated, the recommendation includes an addition 3 to $5 \mathrm{~mL} / \mathrm{kg}$ of body weight fluids 2 hours before departure with free water during heating $[10,21]$. Consumption of isotonic or hypotonic drinks with osmolarity less than 270 mOsm / L any minutes before starting activities is recommended in concentration 0.5 to 0.7 g sodium / L and may contain 4 to $6 \%$ CHO preferably between 15 and $20^{\circ} \mathrm{C}[10,22]$.

\section{Hydration during match}

It's understood by involved professionals on soccer that, due game rules, the opportunities to drink fluids are minimal, which may not allow adequate hydration for players [23]. Making any event that paralyzes match be a profitable situation for athlete rehydrate [11]. In addition, athletes should be stimulated and educated about the state of dehydration in order to self-monitor body changes to seek rehydration according to specific needs of each individual [12]. Consumption of isotonic drinks with osmolarity ranging from 270 to $330 \mathrm{mOsm} / \mathrm{L}$ during match is recommended in concentration 0.5 to $0.7 \mathrm{~g}$ of sodium / L of water and may contain from 6 to $9 \%$ CHO being offered every 15 or 20 minutes in an average volume $150 \mathrm{~mL}$ preferably between 15 and $20^{\circ} \mathrm{C}$ [10].

\section{Hydration after match}

A After match, the objective is to fill deficits of existing liquids and electrolytes. If athlete severe dehydration $(>5 \%$ of body mass) or need rapid rehydration (for example, $<24 \mathrm{~h}$ before the next sporting event) the recommendation is to drink around $1.5 \mathrm{~L}$ of fluids for each $1 \mathrm{~kg}$ body mass lost during activities, necessary to compensate for increased urine production that accompanies rapid consumption of large volumes of fluids [10,21]. Dehydration decreases performance of elite soccer players and as the matches don't have good opportunities for rehydration, this sport poses great challenges for the professionals involved with the athletes' fluid association [24]. Thus, the consumption of hypertonic drinks, with osmolarity below $330 \mathrm{mOsm} / \mathrm{L}$ after departure is recommended in concentration 1 to $1.5 \mathrm{~g}$ of sodium / $\mathrm{L}$ water, and may also contain $\mathrm{CHO}$ in the concentration 9 to $10 \%$ should soon be ingested after match preferably between 15 and $20^{\circ} \mathrm{C}$ [10].

\section{Conclusion}

The soccer is a sport with very particular characteristics regarding hydration, mainly because it doesn't have regular intervals for athletes to drink fluids during matches. As dehydration can decrease performance, fluid intake during matches is important to maintain or increase athletes performance during matches. In addition, elite soccer players must be educated about the importance of drinking fluids before, during and after matches. In summary, Table 1 presents a direct and elaborate outline of evidence-based recommendations for hydration and fluid intake for elite soccer players. 
Table 1: Recommendation of fluid intake and hydration for elite soccer players.

\begin{tabular}{|c|c|c|}
\hline Condition & Recommendations & References \\
\hline \multirow{4}{*}{ Before match } & $5-7 \mathrm{~mL} / \mathrm{kg}$ BW about 4 hours before. & [10] [19] [22] \\
\hline & $\begin{array}{l}\text { If don't produce urine or the urine is dark or concentrated, an additional } 3-5 \mathrm{~mL} / \mathrm{kg} \mathrm{BW} \\
\text { included } 2 \text { hours before and sips at the end of the warm-up ad libitum. }\end{array}$ & \\
\hline & Isotonic or hypotonic sports drinks: & \\
\hline & $\begin{array}{c}0.5-0.7 \mathrm{~g} \text { of sodium / L of water, with osmolarity } \leq 270 \mathrm{mOsm} / \mathrm{L} \text {, concentration } \mathrm{CHO} 4-6 \% \\
\text { between } 15-20^{\circ} \mathrm{C} .\end{array}$ & \\
\hline \multirow{3}{*}{ During match } & $\begin{array}{l}\text { The intake must be sufficient to replace the loss through sweat, with volume and content } \\
\text { previously presented to the players. }\end{array}$ & [10]-[12], [23] \\
\hline & Isotonic sports drinks: & \\
\hline & $\begin{array}{c}0.5-0.7 \mathrm{~g} \text { of sodium / L of water, with osmolarity of } 270-330 \mathrm{mOsm} / \mathrm{L} \text {, concentration CHO } 6 \text { - } \\
9 \% \text { between } 15-20^{\circ} \mathrm{C} .\end{array}$ & \\
\hline \multirow{3}{*}{ After match } & $\begin{array}{l}\text { If dehydration is severe ( }>5 \% \text { of body mass) or rapid rehydration is required (for example, }<24 \mathrm{~h} \\
\text { before the next sporting event) the recommendation is to drink around } 1.5 \mathrm{~L} \text { of fluid for every } 1 \\
\text { kg of deficit of body mass. }\end{array}$ & [10], [21], [24] \\
\hline & Hypertonic sports drinks: & \\
\hline & $\begin{array}{c}\begin{array}{c}1-1.5 \mathrm{~g} \text { of sodium / L of water, with osmolarity } \leq 330 \mathrm{mOsm} / \mathrm{L} \text {, concentration CHO } 9-10 \% \\
\text { between } 15-20^{\circ} \mathrm{C} .\end{array}\end{array}$ & \\
\hline
\end{tabular}

\section{Conflict of Interest Statement}

The author has no conflicts of interest to declare.

\section{Funding Sources}

No funding was received for this study.

\section{Reference}

1. RN Ribeiro LOP Costa (2006) Análise epidemiológica de lesões no futebol de salão durante o XV Campeonato Brasileiro de Seleções Sub 20. Rev Bras Med do Esporte 12[1]: 2-6.

2. M Mohr, P Krustrup, J Bangsbo (2003) Match performance of highstandard soccer players with special reference to development of fatigue. J Sports Sci 21[7]: 519-528.

3. T Strudwick (2016) Soccer Science. Hum. Kinects, [Online]. Available:

4. SM Shirreffs, LF Aragon Vargas, M Chamorro, RJ Maughan, L Serratosa, et al. (2005) The sweating response of elite professional soccer players to training in the heat. Int J Sports Med 26[2]: 90-95.

5. DG Taylor (2017) Water: hydration and sports drink. Second Edi. Elsevier Inc.

6. LF Aragón Vargas, J Moncada Jiménez, J Hernández Elizondo, A Barrenechea, M Monge Alvarado (2009) Evaluation of pre-game hydration status, heat stress, and fluid balance during professional soccer competition in the heat. Eur J Sport Sci 9[5]: 269-276.

7. C Oliveira (2017) Nutrition and Supplementation in Soccer. 5[2]: 28.

8. E Jéquier, F Constant (2010) Water as an essential nutrient: The physiological basis of hydration. Eur J Clin Nutr 64 [2]115-123.

9. SM O Connell (2018) Comparison of a sports-hydration drink containing high amylose starch with usual hydration practice in Australian rules footballers during intense summer training. J Int Soc Sports Nutr 15[1]: $1-10$.

10. MN Sawka, LM Burke, ER Eichner, RJ Maughan, SJ Montain, et al. (2007) Exercise and fluid replacement. Med Sci Sports Exerc 39[2]: 377-390.

11. LM Burke (2010) Journal of Sports Sciences Fluid balance during team sports Fluid balance during team sports. Pp. 37-41.

12. AM Edwards, ME Mann, MJ Marfell Jones, DM Rankin, TD Noakes, et al. Influence of moderate dehydration on soccer performance: Physiological responses to $45 \mathrm{~min}$ of outdoor match-play and the immediate subsequent performance of sport-specific and mental concentration tests. Br J Sports Med 41[6]: 385-391.

13. JJ Zachwieja, SA Anderson, R Murray, ER Eichner, JR Stofan, et al, (2016) Sweat and Sodium Losses in NCAA Football Players: A Precursor to Heat Cramps? Int J Sport Nutr Exerc Metab 641: 641-652.

14.D Czesnik, M de CM Swash (2019) Muscular cramp: causes and management. Eur J Neurol 29: 214-221.

15. B Knechtle, D Chlíbková, S Papadopoulou, M Mantzorou, T Rosemann, et al. (2019)Exercise-associated hyponatremia in endurance and ultra-endurance performance-aspects of sex, race location, ambient temperature, sports discipline, and length of performance: a narrative review. Med 55[9]: 537.

16. KW Braulick, KC Miller, JM Albrecht, JM Tucker, JE Deal (2013) Significant and serious dehydration does not affect skeletal muscle cramp threshold frequency. Br J Sports Med 47 [11]: 710-714.

17. RA Oppliger, SA Magnes, LRA Popowski, CV Gisolfi (2005) Accuracy of urine specific gravity and osmolality as indicators of hydration status. Int J Sport Nutr Exerc Metab 15[3]: 236-251.

18. JC Mentes, B Wakefield, K Culp (2006) Use of a urine color chart to monitor hydration status in nursing home residents. Biol Res Nurs 7 [3]: 197-203.

19. Y Sekiguchi, WM Adams, RM Curtis, CL Benjamin, DJ Casa (2019) Factors influencing hydration status during a National Collegiate Athletics Association division 1 soccer preseason. J Sci Med Sport 22 [6]: 624-628.

20. LD Harper, EJ Stevenson, I Rollo, M Russell (2017) The influence of a $12 \%$ carbohydrate-electrolyte beverage on self-paced soccer-specific exercise performance. J Sci Med Sport 20[12]: 1123-1129.

21. SM Shirreffs, MN Sawka (2011) Fluid and electrolyte needs for training, competition, and recovery. J Sports Sci 29[1]: 37-41.

22. ML Ray, MW Bryan, TM Ruden, SM Baier, RL Sharp, et al. (2017) Effect of sodium in a rehydration beverage when consumed as a fluid or meal. J Appl Physiol 85 [4]: 1329-1336.

23. JA Owen, SJ Kehoe, SJ Oliverm (2013) Influence of fluid intake on soccer performance in a temperate environment. J Sports Sci 31[1]: 1-10.

24. C Ralo Monteiro, I Guerra, T Leite de Barros (2003) Hydration in soccer: A review. Rev Bras Med do Esporte 9 [4]: 243-246. 
(c) (9) This work is licensed under Creative

To Submit Your Article Click Here: Submit Article

DOI: 10.32474 /SJFN.2020.03.000169

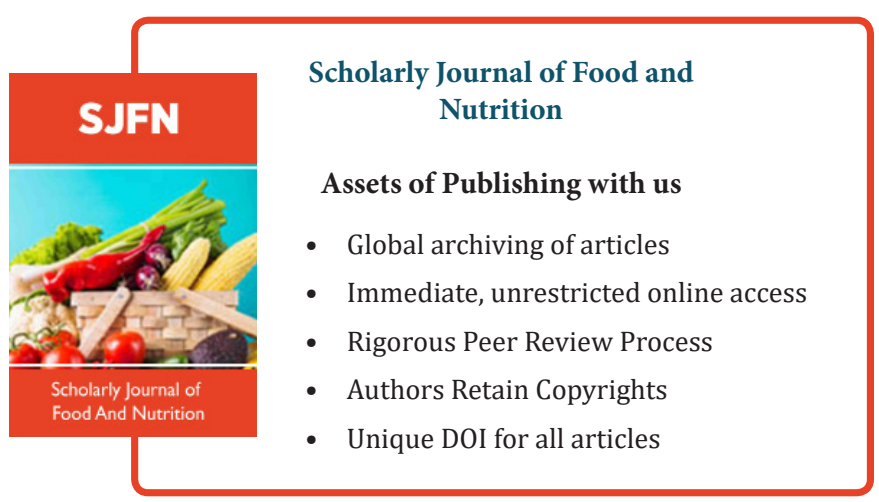

